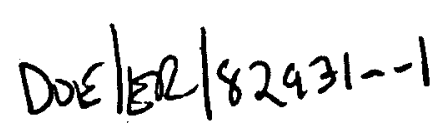

\title{
Final Performance Technical Report
}

Accusol, Inc.

January 15,2002

Project Summary: Phase I, FY2000, Award Number DE-FG02-00ER82931

Final Report

Project Title: "Solid State Device for Two-Wire, Downhole, Temperature Measurement as a Function of Current"

Accusol Inc. carried out the following project during the September 2000 to February 2001 timeframe under award number DE-FG02-00ER82931.

Abstract: Several metals systems were reviewed for their potential to act as resistive temperature devices for downhole, geothermal application. Platinum metal was selected as the metal of choice. Platinum was plated onto 5 mil copper wire, and then subsequently coated with Accusol's proprietary ceramic coating. The copper was etched out in an attempt to make a pure platinum, high resistance, resistivetemperature device. The platinum plating on the wire cracked during processing, resulting in a discontinuous layer of platinum, and the element could not be formed in this way.

\section{Project Goal}

Accusol proposed to develop a new type of sensor for measuring the temperature of gas as deep as 15000 feet below the earth's surface using a resistive temperature device. The proposal was to make a resistive wire element, coated with Accusol's proprietary ceramic coating, and then calibrate this wire as the resistive device. Because the wire would be coated with ceramic, the potential long term stability of the element would be ensured, relative to polymer coated wires, for example, which could not stand the application temperatures, of up to $350^{\circ} \mathrm{C}$ for thousands of hours of continuous operation. Also, Accusol's coating technology allows ceramic coating as thin as 2 mils, which makes the sensitivity and response time for the temperature sense element favorable.

\section{Summary of Approach}

A large number of alloys were investigated to choose one with appropriate temperature resistance properties. A number of custom wire fabricators were also contacted to inquire about having wire drawn of some chosen alloy. The best candidate identified was platinum. Platinum has an excellent linear dependence of resistance on temperature, and is nominally 10 times the bulk resistivity of copper. ${ }^{1}$ In order for the platinum element to have a very high absolute resistance, however, it needs to be very thin. So, it was decided that platinum could be plated onto a very thin copper wire substrate $(5$ mils diameter). Then, the platinum plated copper wire would be coated with ceramic, formed into a sense element, and fired. Then, electrical connection to the platinum surface would be made, and the copper substrate could be etched out. In its application, the temperature

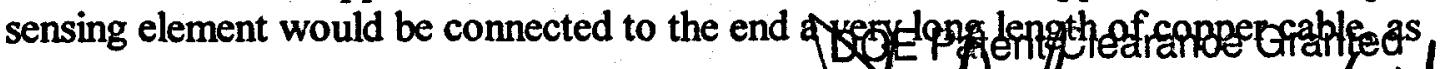

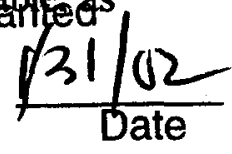




\section{DISCLAIMER}

This report was prepared as an scocunt of work sponsored by an agency of the United States Government. Neither the United States Governmeat nor any ageacy thereof, nor any of their employees, makes any warranty, express or implied, or assumes any legal liability or responsibility for the sceuracy, completeness, or usefulness of any information, apparatus, product, or process disclosed, or represents that its use would not infringe privately owned rights. Reference herein to any specific commercial product, process, or service by trade name, teademart, manufactures; or otherwise does not necessarily constitute or imply its endorsement, recommendation, or faviring by the United States Government or any agency thereof. The views and opinions of authors expressed herein do not necessarily state or reflect those of the United States Government or any agency thereof. 


\section{DISCLAIMER}

Portions of this document may be illegible in electronic image products. Images are produced from the best available original document. 
long as 15,000 feet, which would have its own resistance, on the order of 1 to $10 \mathrm{k}$-ohm. The resistance of the temperature sense element would have to be high enough that the relative resistance of the lead cables was significantly smaller than the resistive element itself. Figure 1 below shows the schematic of the proposed sensor system.

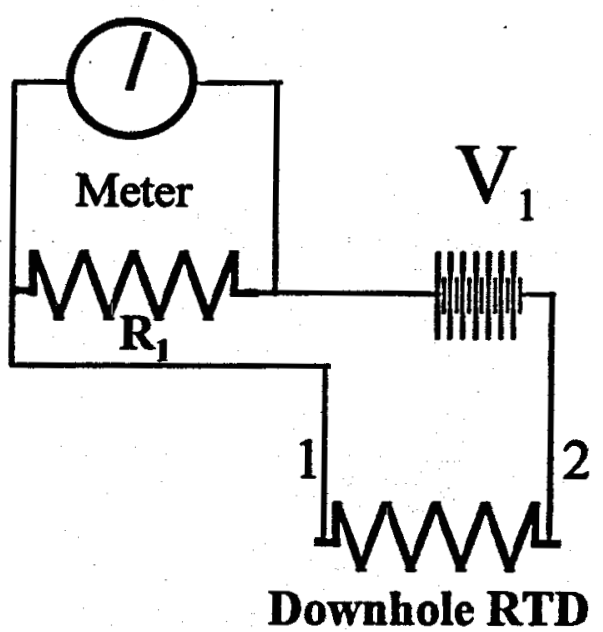

Figure 1. Downhole RTD is much higher resistance than electrical leads 1 and $2, R_{2}$, thus requiring only 2 wires. $R_{1}$ is in series with RTD but is on the surface, adjacent to current source.

The following simple calculation shows the relationship between the resistance value of the Downhole RTD and $R_{1}$. The value, $R_{2}$, is the resistance value of the downhole leads, labeled 1 and 2 in Figure 1 . Since $V_{1}, i$, and $R_{1}$ are all well known, then the resistance of : RTD is easily determined by a two-wire system.

$$
\begin{aligned}
& \mathrm{V}_{1}=i R_{1}+i(R T D)+i R_{2} \\
& \therefore R T D=\frac{\mathrm{V}_{1}}{i}-\left(R_{1}-R_{2}\right) \\
& \text { If } R_{1} \gg R_{2} \text {, then } \\
& R T D=\frac{\mathrm{V}_{1}}{i}-R_{1}
\end{aligned}
$$

If the resistance of the lead wires, numbered 1 and 2 in Figure 1 , is called $R_{2}$, then this calculation assumes that $R_{1} \gg R_{2}$ and that $R T D \gg R_{2}$. This point is the main reason that this super RTD is superior to conventional RTDs. Conventional RTDs are made of copper, and can never be much greater resistance than $R_{2}$ in practice. The only way that the copper RTD could be much higher in resistance than $R_{2}$ is if the RTD itself were physically very large. The goal of this work was to choose a metal other than copper, so that the RTD could be made quite compact, and still be very sensitive and accurate 


\section{Phase I Successes}

In the Phase I activity of this project, Accusol identified that the best metal system from which to fabricate a resistive temperature device is platinum. Platinum has a very highly linear temperature versus resistance curve in the range of interest, $0^{\circ} \mathrm{C}$ to $325^{\circ} \mathrm{C}$. Because the resistance of the platinum is nominally 10 times that of copper in the same temperature range, an approach to use an exceedingly thin layer of platinum as the resistive element was attempted. In this way, the actual sensing element, a very thin platinum, would have a net electrical resistivity much higher than 15000 feet of 16 gauge copper wire. The two major components of the program, then, became, successfully plating platinum onto a copper substrate, and then fabrication of that into a temperature sensing element.

\section{Platinum-plated wire}

Over 500 alloys were evaluated based on existing literature, and the linearity of platinum metal was seen to have tremendous advantage. Therefore, it was decided that a good approach was to electro-deposit very thin platinum onto 5 mil copper wire. Subsequently, the platinum-plated copper wire would be coated with the Accusol ceramic, and then the copper would be removed electrolytically. Platinum has a higher oxidation potential than copper, so this was accomplished in straightforward manner by choosing appropriate potential. Copper is known to oxidize at $0.34 \mathrm{~V}$, but platinum oxidizes $1.2 \mathrm{~V}$, so it is straightforward to selectively remove the copper core by choosing: the oxidation potential to be less than $1.2 \mathrm{~V}$ and greater than $0.34 \mathrm{~V}^{2}$. Figure 2 shows an end-on view of platinum-plated copper wire, prior to etching away copper. The thin layer of platinum is plainly visible as light grey, and the copper core is dark. A platinum: plating chemistry from Technic, Inc. was successfully used, but required that we prepare a plating bath through which the copper wire could be passed. Platinum was plated at $90^{\circ} \mathrm{C}$, with a residence time of 2 minutes, and potential less that $4.0 \mathrm{~V}$, with slight agitation of the solution. These are standard parameters, as provided by Technic.

A significant effort was spent on developing the process to plate platinum onto 5 mil copper wire. The copper wire was lead by pulleys and smooth Teflon surfaces under the surface of the plating solution. It was observed that significant frictional drag was placed on the wire in this system because the 5 mil wire would occasionally break during the plating process as a result of being pulled through a relatively high friction system. 


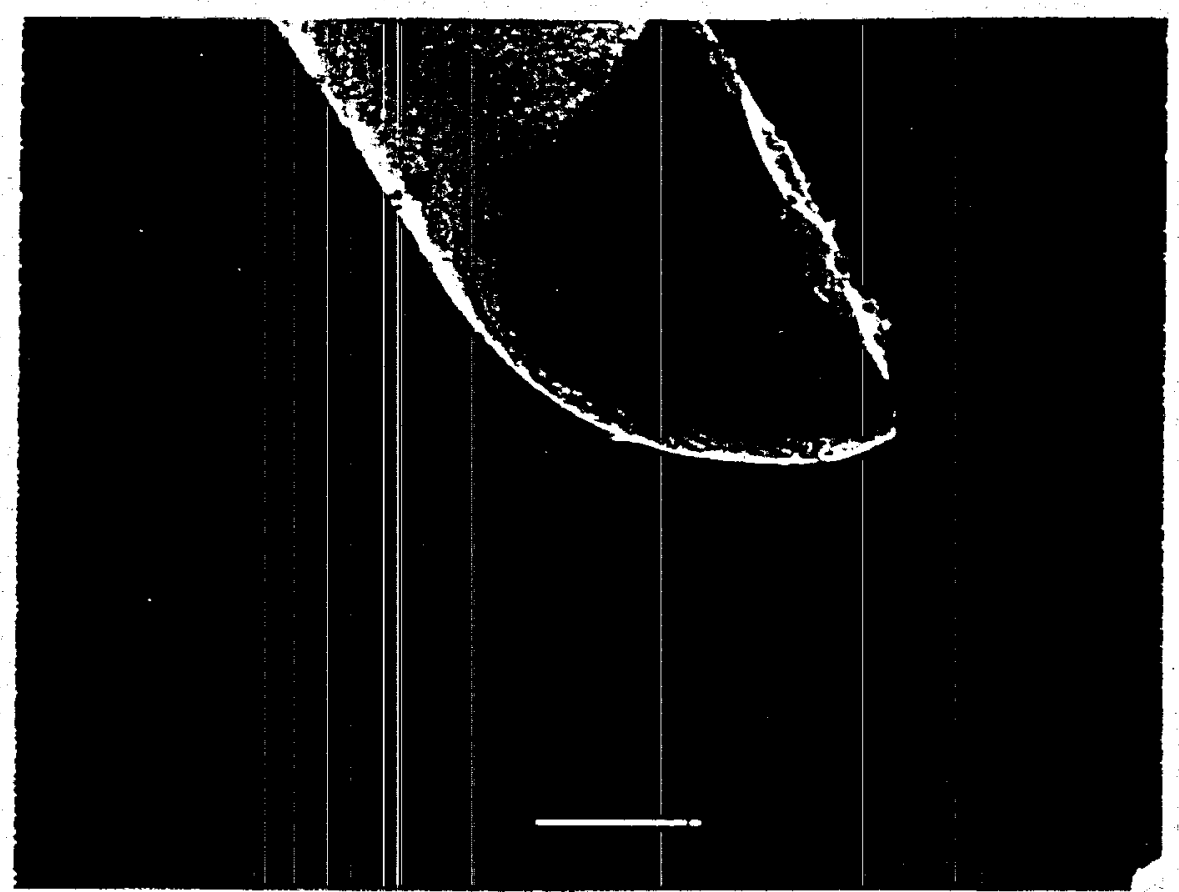

Figure 2. Cross section of 5 mil copper core wire with thin layer of platinum from electrodeposition process. The thickness of the platinum is estimated from SEM to be about 1.5 micron.

The copper can be selectively removed by adjusting the oxidation potential in a dilute. sulfuric acid bath. Figure 2.1 shows a hollow platinum core. And Figure 2.2 shows the same core on its edge. From electron microscopy, and viewing "edge on"perspectives like in Figure 2.2, it is straightforward to determine that the thickness of the platinum coating is 1.5 micron. Both Figure 2.1 and Figure 2.2 show how fragile the unsupported 1.5 micron film of platinum is. 


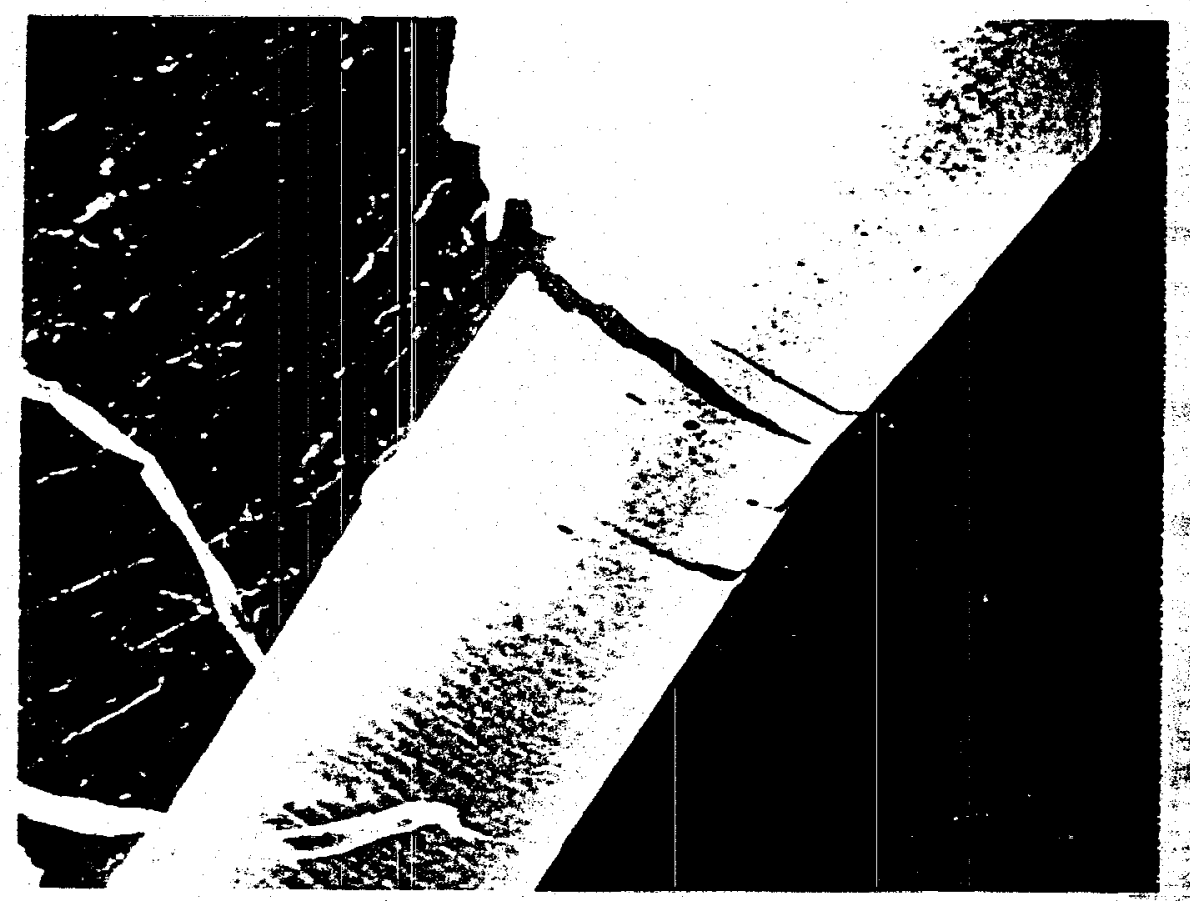

Figure 2.1 Platinum coating without copper core.

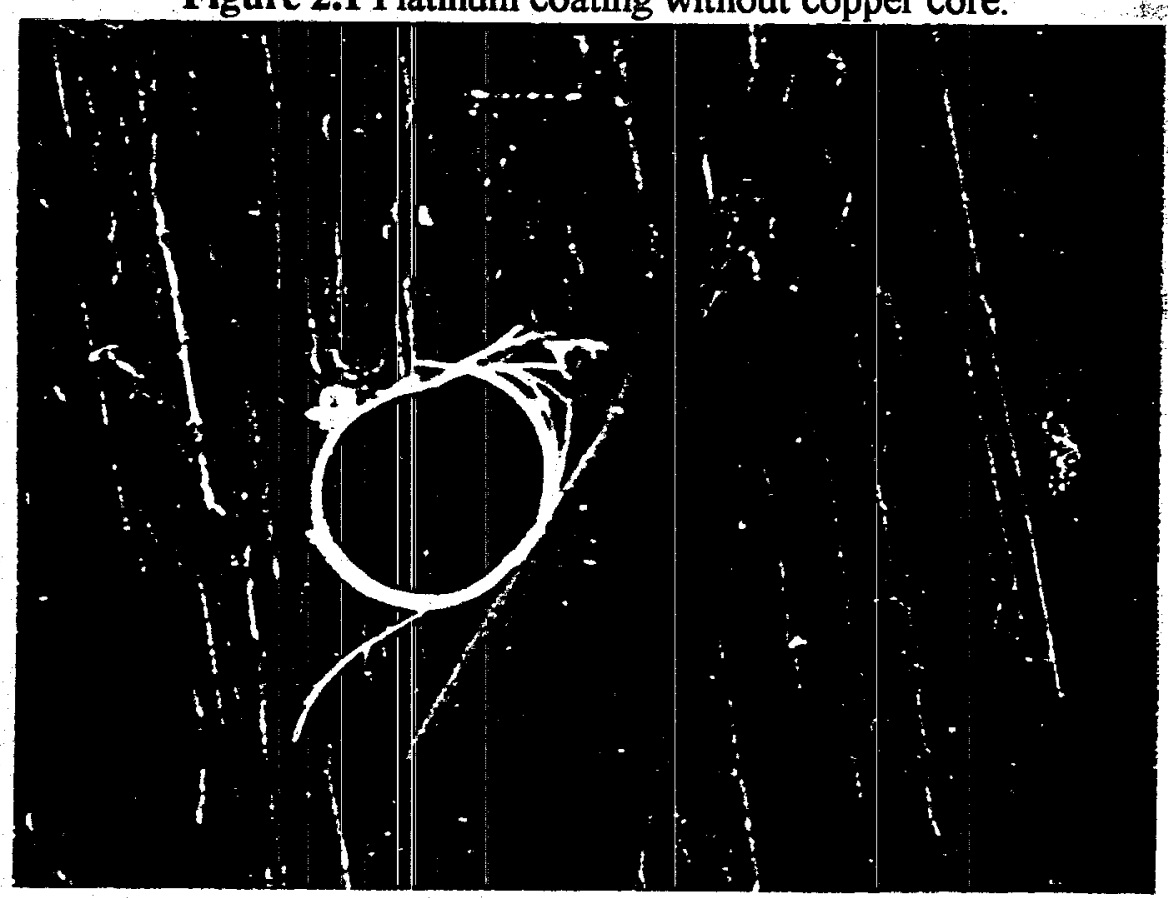

Figure 2.2 Platinum coating, viewed edge on without copper core.

\section{Temperature Sensing Element Fabrication}

The platinum-plated copper wire can be coated with ceramic to generate a structure shown schematically in Figure 3. This represents an element. Ideally, the exposed ends of the element can be electrically connected so that the resistance of the element can be used to indicate temperature. However, due to the fragility of the very thin film of 
platinum, making this electrical contact with soldering or welding proved problematic. Whereas we were successful in making an electrical connection to the platinum surface, the electrical measurements revealed that the platinum film within the element was discontinuous, and therefore, no resistance measurement could be made. The defects in the platinum-plating surface, as shown by SEM, suggest that the process by which the copper wire was pulled through the plating bath actually drew the wire slightly, and caused the annular cracking on the platinum coating. Figure 2.1 above, and other SEM photos strongly suggest this failure mechanism. SEM data collected at Technic, Inc. also strongly suggest that the platinum coating was damaged during wire handling at the plating step.

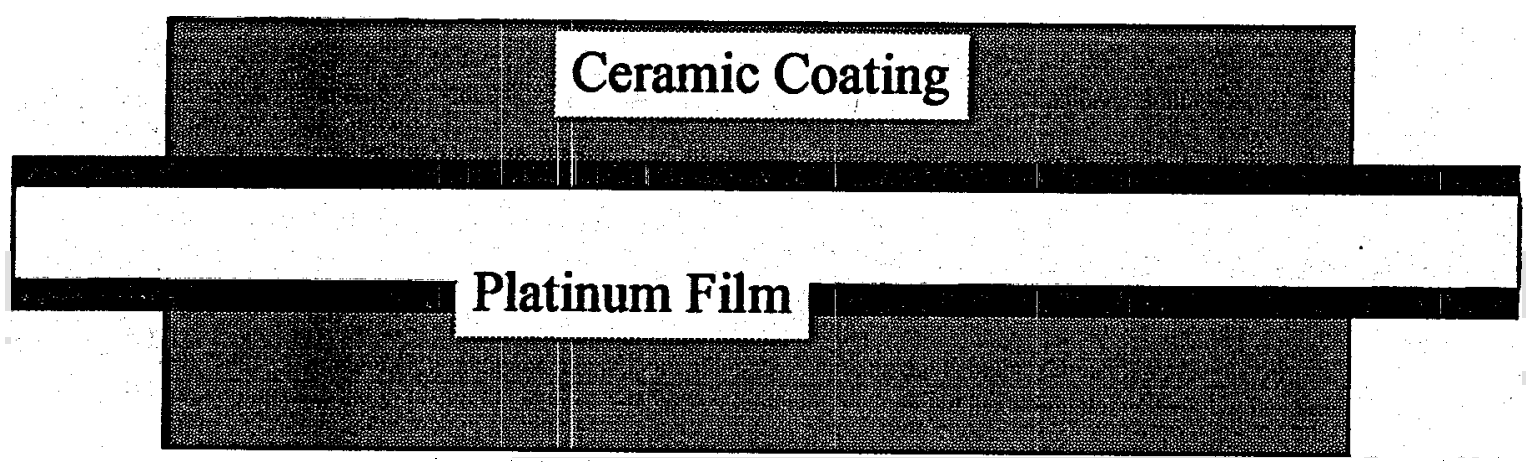

Figure 3. Schematic of desired resistive temperature sense element. Notice that the core is hollow because the copper has been removed. The platinum film remains attached to the ceramic coating, because the ceramic coating was applied and fired PRIOR to the etching of the copper.

Cross sections of wire and coatings this thin do not reveal much information under optical inspection at 200x magnification as shown in Figure 4. The platinum and the ceramic coating are too thin to be viewed under optical magnification. However, the thickness of the fully fired ceramic coating can be measured easily with digital calipers and was shown to be 1 mil thick. Furthermore, the finished, fired wire has a glossy appearance, indicating good adhesion and proper firing behavior of the ceramic coating.

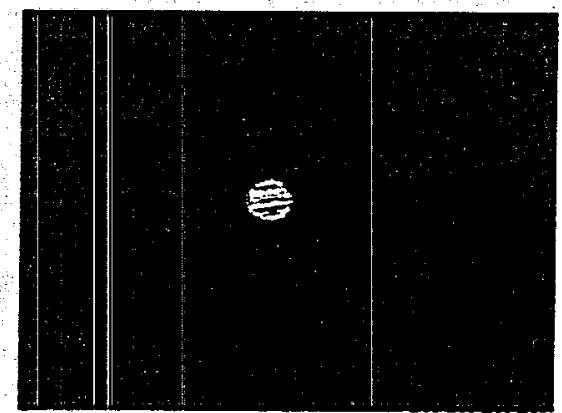

Figure 4. Optical view of cross section at $200 x$ of ceramic coated, Pt-plated wire. Not much detail is available from optical microscopy because the layers are too thin. 
In summary, then, the successes of the Phase I program are as follows:

1. Identified platinum as metal of choice for resistive temperature element.

2. Developed a platinum plating process to apply 1.5 micron $\mathrm{Pt}$ to $5 \mathrm{mil}$ copper wire in a continuous process.

3. Coated ceramic material onto Pt-plated copper wire.

4. Removed copper core electrolytically.

5. Characterized thickness of platinum metallization.

The failure to make a device resulted from the fact that the plated platinum was not a continuous layer. SEM showed a high frequency of annular cracks in the platinum layer due to the axial tensile stresses applied to the 5 mil plated copper wire during the plating process. This problem could be easily addressed with superior wire handling machinery that could advance the wire through a system, while minimizing the axial tensile stresses that create the cracks in the platinum coating. Therefore, following the etching of the copper core to generate the structure shown schematically in Figure 3, the electrical continuity through the platinum element was not observed. Indeed, measurement of the resistance indicated that the path was electrically open, and not measurable with an Agilent Technology digital multimeter, 34401A.

\section{Conclusion}

The approach taken is technically sound, however, the tools available to Accusol were not optimal for achieving a mechanically robust sensing element. The 5 mil copper wire is substantially delicate that during the process of being drawn through the platinumplating bath, it stretches slightly, and cracks the thin, fragile platinum coating. Since SEM analysis showed the thickness of this platinum coating to be 1.5 microns, any slight stretching of the copper would result in platinum cracking. It is likely that with more sensitively balanced wire handling equipment, the desired element could be made using the general approach described here.

\footnotetext{
' Dyos, G.T., Farrel, T, "Electrical Resistivity Handbook" Peter Peregrinus Limited, ? 1992.

${ }^{2}$ Bard, A.J., Faulkner, L.R., "Electrochemical Methods, Fundamentals and Applications" John Wiley \& Sons, 1980, page 699.
} 